\title{
As crianças e suas narrativas audiovisuais:
}

o que nos contam com suas produções

Children and their audiovisual narratives:

\author{
what their productions tell us
}

\section{Los niños y sus narrativas audiovisuales: \\ lo que nos cuentan sus producciones}

\author{
Renata Gazé \\ Universidade Federal do Estado do Rio de Janeiro (Unirio), Rio de Janeiro/RJ - Brasil
}

\begin{abstract}
Resumo
Hoje, muitas crianças convivem com narrativas audiovisuais nas telas da televisão, do celular, do cinema e dos computadores de uma forma geral. Como se relacionam com esse vasto universo, envolvendo sons e imagens, e como produzem suas próprias narrativas com essa mesma linguagem? O presente artigo traz um estudo sobre a relação de crianças de 8 a 11 anos com a produção de narrativas audiovisuais, entendendo que produzir também é uma maneira de se apropriarem dessas narrativas e de mostrarem o repertório que trazem, o que pensam, como entendem e como querem contar suas próprias histórias com áudio e vídeo. Por fim, aponta algumas contribuições para processos de ensino e aprendizagem. A metodologia utilizada foi a pesquisa-intervenção, e o campo foi realizado através de oficinas de criação e produção de narrativas audiovisuais.
\end{abstract}

Palavras-chave: Narrativas, Audiovisual, Crianças, Infância, Cultura

\begin{abstract}
Nowadays, many children live with audiovisual narratives on the screens of television, mobile phones, movies and computers in general. How do they interact with this broad universe involving sounds and images and how do they produce their own narratives with this same language? This article presents a study about the relationship of 8- to 11-year-old children with the production of audiovisual narratives, considering that when they produce it, it is also a way of appropriating these narratives and showing their repertoire, what they think, how they understand and how they want to tell their own stories with audio and video. Finally, it points out some contributions to learning teaching processes. The methodology used was intervention research and the field work consisted of audiovisual narrative production workshops.
\end{abstract}

Keywords: Narratives, Audiovisual, Children, Childhood, Culture

\section{Resumen}

Hoy en día, muchos niños conviven con narrativas audiovisuales en las pantallas de la televisión, del teléfono móvil, del cine y de los ordenadores en general. ¿Cómo se relacionan con este amplio universo que involucra sonidos e imágenes y cómo producen sus propias narrativas con este mismo lenguaje? Este artículo trae un estudio sobre la relación de los niños de 8 a 11 años con la producción de narrativas audiovisuales, teniendo en cuenta que producir también 
es una forma de apropiarse de estas narrativas y de exhibir el repertorio que traen, lo que piensan, cómo entienden y cómo quieren contar sus propias historias con audio y vídeo. Finalmente, apuntan algunas contribuciones a los procesos de enseñanza y aprendizaje. La metodología utilizada fue la investigación-intervención y el trabajo de campo se llevó a cabo a través de talleres de creación y producción de narrativas audiovisuales.

Palabras clave: Narrativas, Audiovisual, Niños, Infancia, Cultura

\section{Introdução}

Hoje, muitas crianças convivem com narrativas audiovisuais nas telas da televisão, do celular, do cinema e dos computadores de uma forma geral. Como se relacionam com esse vasto universo, envolvendo sons e imagens, e quais experiências e repertórios trazem a partir do que vivenciam nessa cultura audiovisual? Como produzem suas próprias narrativas com imagens e sons, 0 que nos contam, o que já sabem e o que aprendem com esse processo?

Este artigo traz parte de uma pesquisa de mestrado, realizada com crianças de 8 a 11 anos, criando e produzindo suas histórias com imagens e sons - aqui chamadas de narrativas audiovisuais -, em oficinas de criação, produção e edição de vídeos, com desenvolvimento de roteiros, cenários, figurinos e personagens.

Adotaram-se como referencial teórico os estudos culturais latinoamericanos, que apontam a cultura como sendo produzida nos muitos espaços por onde circulamos e pelas diversas mediações que acontecem neles. As narrativas audiovisuais fazem parte desse universo, e o recorte do trabalho aqui trazido buscou perceber como as crianças criam utilizando áudio e vídeo, o que gostariam de contar e o que mais poderiam aprender.

A metodologia utilizada foi a pesquisa-intervenção, e as crianças construíram a pesquisa junto com o(a) pesquisador(a). Olhar para as crianças como produtoras de cultura e autoras de suas próprias histórias, através das produções audiovisuais realizadas por elas, é também perceber como, criando e contando histórias, valores podem ser construídos e significados podem ser repensados.

\section{Fundamentação teórica}


Com a colaboração dos estudos culturais latino-americanos e dos conceitos de narrativa, experiência e infância em pesquisa, buscamos compreender a influência que o audiovisual exerce (ou pode exercer) nas maneiras de as crianças criarem e narrarem suas histórias. Entendendo a cultura como um processo que acontece nas relações sociais e nos locais por onde os sujeitos circulam ou se encontram, Canclini (2009) nos traz os estudos sobre recepção e apropriação de bens e mensagens, lembrando que um mesmo objeto ou uma mesma mensagem podem ter diferentes usos e apropriações.

Uma narrativa audiovisual, enquanto mensagem, chega para os sujeitos através dos locais acessíveis a eles, sejam físicos ou virtuais. E esses mesmos sujeitos, que neste estudo são as crianças, também podem produzir suas narrativas e as tornar conhecidas, se assim desejarem, divulgando-as através dos locais que igualmente são acessíveis a eles. Processos de significação acontecem enquanto todas essas narrativas circulam e, assim, quanto mais 0 acesso - tanto para recepção quanto para produção de narrativas - estiver ao alcance das crianças, mais mensagens vão circular e mais significados serão produzidos, enriquecendo as possibilidades de estudo e de produção de conhecimento.

A concepção de infância que guiou este estudo - entendendo também a infância como uma construção social de cada época - é aquela que entende as crianças como produtoras de cultura e com total capacidade de intervir e participar ativamente das questões e desafios que nos são postos todos os dias, inerentes à vida em sociedade e importantes para o crescimento e a formação de todos nós. Novas situações e novas experiências nos são colocadas a cada dia, nas quais podemos crescer juntos, uma visão de infância como a que Macedo et al. (2012) nos falam:

...procuramos com nossos estudos e na relação efetiva com as crianças, construir uma visão de infância que compreenda as crianças como sujeitos inseridos na cultura, sujeitos com experiências plurais, sujeitos de seu tempo, sujeitos de direitos, seres dotados de capacidade de pensar e de se posicionar sobre o mundo em que estão inseridos, sobre a vida que vivem. (p. 100)

Destaque-se que o mundo das crianças sempre foi habitado por muita imaginação e que as narrativas audiovisuais, em alguma instância, estimulam ainda mais o imaginário infantil e a construção de novas histórias por elas 
próprias. Quando aprendem a narrar, também através da leitura e da escrita, as crianças já tiveram bastante contato com as narrativas audiovisuais, mas não necessariamente com a possibilidade de produzir suas próprias histórias dessa maneira, o que pode vir a ser uma experiência bastante enriquecedora.

As narrativas, de diversas formas e em variados suportes, estão presentes no dia a dia das crianças e as convidam a refletir criticamente, a viverem emoções, a terem vontade de as acompanhar por um determinado período ou simplesmente decidirem que aquilo ali não as interessa e que não vão dar-lhes atenção. No entanto, todas elas, de alguma maneira e em algum momento, se fazem presentes na vida das crianças e colaboram para sua formação. Como nos diz Fernandes (2009):

Todas as espécies de narrativas fazem parte da formação da criança, constituem seu "mar de histórias" e trazem possibilidades de criação, combinando-se e juntando-se numa hibridação entre contos orais, mídia e literatura podendo ser cada vez mais ampliadas, recombinadas e recriadas em novas histórias. (p. 220 e 221)

Muitas dessas narrativas estão nas telas da televisão, do cinema, dos computadores e dos celulares, no formato de histórias e mensagens contadas com áudio e vídeo. O termo "mídia", que significa meio, pode ser utilizado para também denominar o grande sistema em que estão incluídos os meios de comunicação, as mensagens que esses meios veiculam e os suportes por onde circulam essas mensagens. Um grande sistema, portanto, em que todos nós estamos inseridos e interagindo o tempo todo, elaborando significados, influenciando e sendo influenciados por tudo o que nos chega. Com as crianças, não é diferente, conforme nos colocam Ribes, Salgado e Jobim e Souza (2006):

É cada vez mais evidente o significado que a mídia tem assumido na configuração do repertório imaginativo das crianças, ao oferecer-Ihes referências simbólicas, narrativas e valores estéticos, que compõem o enredo de suas fabulações, as identidades dos personagens que criam e as linguagens que comunicam e significam suas experiências lúdicas transformadas em textos e imagens. (p. 165)

Portanto, a opção por trabalhar com narrativas audiovisuais se deu por acreditarmos serem elas, de alguma maneira, encantadoras, conhecidas das crianças e com grandes possibilidades de atrair o seu interesse por assistir e brincar de contar e recontar suas próprias histórias dessa forma. Lembrando 
ainda Larrosa (2002), que nos convida a pensar sobre como acontece de fato uma experiência:

A experiência, a possibilidade de que algo nos aconteça ou nos toque, requer um gesto de interrupção, um gesto que é quase impossível nos tempos que correm: requer parar para pensar, parar para olhar, parar para escutar, pensar mais devagar, olhar mais devagar e escutar mais devagar; parar para sentir, sentir mais devagar, demorar-se nos detalhes, suspender a opinião, suspender o juízo, suspender a vontade, suspender o automatismo da ação, cultivar a atenção e a delicadeza, abrir os olhos e os ouvidos, falar sobre o que nos acontece, aprender a lentidão, escutar aos outros, cultivar a arte do encontro, calar muito, ter paciência e dar-se tempo e espaço. (p.24)

Assim, o que narramos hoje pode trazer experiências de fato vivenciadas, ou pode trazer apenas o que observamos. Para narrar, podemos trazer o repertório que temos, algumas das experiências por nós vividas e algumas observações do que acontece ao nosso redor. Hoje, também podemos escolher, dentre diversos suportes, formatos e linguagens, como vamos narrar o que queremos. O audiovisual é um desses suportes, com formato e linguagem próprios, e foi o escolhido aqui. $E$ dentre os muitos eixos possíveis quando pesquisamos com produção audiovisual (MARTIN, 2003), destacamos que a escolha se deu por pesquisar com as crianças a partir de apenas quatro eixos dessa linguagem: roteiro, produção, câmera e edição.

\section{Metodologia}

A metodologia utilizada foi a pesquisa-intervenção, compreendida como aquela que tem o objetivo de tentar mudar algo junto com os sujeitos nela envolvidos e na qual todos são corresponsáveis pela mudança. Uma pesquisa que aconteceu com as crianças, e não sobre as crianças, já que elas foram coautoras e, nesse sentido, pesquisador(a) e pesquisados construíram juntos o campo de pesquisa.

Participaram crianças de 8 a 11 anos, convidadas publicamente por via de cartazes espalhados pela universidade e através de conversas com seus pais (estudantes da universidade em questão). O grupo de crianças participantes atuou em sete oficinas de criação e produção de narrativas audiovisuais, nas quais aconteceram rodas de conversas, jogos e brincadeiras sobre as maneiras de se criar e produzir histórias com áudio e vídeo. 
Realizaram-se atividades práticas, com criação de roteiros, cenários, figurinos, objetos de cena, uso da câmera para gravação, uso do computador para edição e definições de como atuariam em cada história. Participaram cerca de 10 crianças, e foi com base nas suas produções e falas que a pesquisa se desenvolveu.

\section{Análise das narrativas}

Criança A: A gente vai fazer um filme de verdade. Você disse!

Pesquisador(a): Sim. A gente vai fazer um filme de verdade.

Criança A: Ah... Bom.

Criança B: E quando a gente fez a narração, com o microfone, você falou que ia passar ali. (E apontou a televisão).

Analisando o processo e as narrativas audiovisuais produzidas pelas crianças, vale o destaque para as muitas vezes, durante as oficinas, em que elas mostraram sua relação com o audiovisual e seus conhecimentos sobre a produção dessas narrativas. O diálogo em destaque, por exemplo, aconteceu no primeiro dia de oficina e mostra que as crianças queriam "fazer um filme" e que entendiam que esse fazer incluía o "passar o filme na tela para outros verem", dois momentos que pudemos viver posteriormente nas oficinas.

Continuando as conversas e apresentando as funções dos profissionais que costumam fazer parte de uma equipe durante a realização de um filme, através de uma brincadeira, a proposta era que tentassem descobrir quais eram as funções e quem estava fazendo o que nas fotos apresentadas durante o jogo. Elas não tiveram dificuldades, reconheceram logo quase todas as funções (roteirista, ator, maquiador, figurinista, editor, narrador, produtor e artista gráfico) e responderam rapidamente qual gostariam de ter:

Pesquisador(a): E se vocês pudessem escolher uma função dentro da equipe que precisa para fazer um filme, o que vocês gostariam de ser?

Criança C: Maquiadora ou figurinista.

Criança A: Roteirista.

$E$ as respostas se confirmaram ao longo das atividades durante os dias de oficina. A Criança $A$, por exemplo, realmente gostava e mostrava mais facilidade para escrever e, muitas vezes, fazia também os respectivos desenhos que acompanhavam cada parte de sua história escrita, como numa espécie de 
filme. Mais à frente, quando terminamos as oficinas, contou-nos que, naquele momento, estava criando gibis também.

Pensando em como gravar cada história, a Criança D assumiu a postura de diretora, espontaneamente, durante uma brincadeira entre elas. Sentada ao lado da câmera, enquanto as demais mostravam seus roteiros:

Criança D: Próximo! Vamos lá!

A Criança D, nos outros dias, gostou muito de ser a diretora de seu filme e com frequência queria dar sugestões nas histórias criadas pelas demais crianças, especialmente, na hora da gravação das cenas.

Durante a preparação dos cenários e figurinos, antes do início das gravações, a Criança A comentou, com muita propriedade, sobre como faríamos uma cena do filme da Criança $B$, em que teria que aparecer o céu durante a noite:

Criança A: Então a gente vai filmar o filme dela à noite? Que doideira!

Pesquisador(a): É porque o dela vai precisar de uma lua, se for usar a lua de verdade, a gente faria à noite.

Criança A: Ah, ou a gente apaga a luz e faz!

As crianças desenvolveram suas histórias em formato de roteiro - criando livremente textos e desenhos - e sabiam o que queriam mostrar e como mostrar. Sabiam igualmente o que era parte de sua imaginação, ali materializada num roteiro, e sabiam, ainda que intuitivamente, que passaríamos por algumas etapas de produção até que suas histórias estivessem finalizadas e prontas para serem exibidas em alguma tela. A análise das narrativas se deu a partir dos quatro eixos mostrados e experimentados durante as oficinas: roteiro, produção, gravação (uso da câmera) e edição.

\begin{tabular}{|l|l|}
\hline ROTEIRO & $\begin{array}{l}\text { Criação da história com texto e } \\
\text { desenhos. }\end{array}$ \\
\hline PRODUÇÃO & $\begin{array}{l}\text { Criação de cenários, figurinos e objetos } \\
\text { de cena e organização da equipe e das } \\
\text { funções para produção e gravação. }\end{array}$ \\
\hline GRAVAÇÃO (USO DA CÂMERA) & $\begin{array}{l}\text { Gravação e escolhas de } \\
\text { enquadramentos. }\end{array}$ \\
\hline EDIÇÃO & $\begin{array}{l}\text { Montagem final da história, efeitos e } \\
\text { mudanças possíveis. }\end{array}$ \\
\hline
\end{tabular}




\subsection{ROTEIRO - "Eu faço histórias e quero transformar em filmes!"}

Pesquisadora: Alguém aqui já fez filme?

Criança A: Eu faço histórias e quero transformar em filmes!

Criança B: Eu tô com uma história toda na cabeça, e depois que todo mundo chegar, eu posso contar. Não trouxe papel, mas tá na minha cabeça, e eu posso contar.

As crianças, pelo seu conhecimento de tevê e cinema, já entendiam esse processo do colocar uma ideia da cabeça no papel e transformar numa história de filme. Todas criaram seus roteiros e colaboraram para as ideias dos roteiros das demais. E assim, as histórias foram surgindo.

\subsection{PRODUÇÃO - espaço de brincar de fazer filmes}

Criança $E$ e Criança $A$ olhando suas histórias e comentando o que era necessário ter para gravar:

Criança E: O meu é facinho. Só o sol, uma grama com flores, uma princesa e um castelo.

Criança A: O meu é mais fácil ainda, só um duende, um abacaxi gigante e outra dimensão.

Conversas como esta mostram que as crianças tinham conhecimento sobre a produção e a transformação das histórias em audiovisual. Em outros momentos, indicavam que também sabiam adaptar e negociar, quando algo não estava saindo conforme o planejado. A Criança B nos relatou que a dificuldade de criar um monstro de quatro cabeças foi um momento bastante desafiador durante a produção de seu filme, mas que isso foi contornado, e ela aprovou o monstro ter ficado com três cabeças.

Quando de fato produzem uma narrativa audiovisual, as crianças mostram parte do repertório que têm sobre como criar e, especialmente, sobre como contar uma história assim, e ainda, sobre como devem adequar o conteúdo escolhido e criado por elas para a linguagem audiovisual. A produção é uma das etapas-chave de um processo de realização de um projeto audiovisual. O roteiro tem todas as ideias encadeadas, mas é preciso transformá-las em realidade, e, para isso, a produção se faz fundamental. Gardies (2008) nos lembra que o cinema trouxe profissionais e talentos de outras áreas das artes e conseguiu integrá-los na produção de uma história em formato de filme:

O cinema fez uso pródigo de tudo o que veio antes dele. Quando ganhou a fala em 1930, requisitou o serviço de escritores; com o sucesso da cor, arregimentou 
pintores; recorreu a músicos e arquitetos. Cada um contribuiu com sua visão, com sua forma de expressão. (p. 21)

As crianças mostraram que entendem que todos esses talentos, de alguma maneira, são requisitados para se produzir uma narrativa audiovisual. Não utilizaram os nomes técnicos de cada função ou profissão, mas responderam da maneira como conheciam:

Pesquisador(a): O que vocês foram no filme de vocês?

Criança B: A gente foi desenhista.

Criança D: Roteirista.

Criança B: A gente foi artista, narradora. A gente escolheu as roupas.

Criança D: A câmera.

Criança B: A gente fez a produção.

\subsection{CÂMERA - a câmera pode se tornar um brinquedo}

A câmera pode se tornar um brinquedo, e as crianças rapidamente passam a lidar com ela dessa maneira, como nestes momentos:

Criança $A$ e Criança $B$, brincando com a câmera que estava ligada apenas para registro. Criança $A$ em frente à câmera, pulando, e Criança $B$ gravando.

Criança B: Fala o seu nome.

Criança A: Oiê!!

Criança B: Quantos anos você tem?

Criança A: Oito.

Criança B: De onde você fala?

Criança A: Do Rio de Janeiro.

Cenas como essa mostram que esse experimentar-se em frente à câmera demonstra o que conhecem pelo modo como reproduzem as cenas vistas na TV e em outros vídeos. Salgado (2005) nos diz que, quando as crianças criam suas próprias narrativas, elas alternam os papéis de autor e personagem e, assim, também compõem suas identidades. Ela também nos fala sobre o quanto o universo lúdico infantil é rico e estimulante, para que a criança crie suas histórias a partir dele e fale sobre si mesma nas histórias criadas:

É também nesse universo que as crianças, ao criarem narrativas, veem-se como autores e personagens das histórias que inventam e deparam-se, no espelho refletido por essas histórias, com a imagem dos heróis e vilões que constroem para suas próprias vidas. Brincando, jogando e criando narrativas, as crianças estão falando de si próprias, de seus medos, coragem, angústias, sonhos e ideais. (SALGADO, 2005, p. 238) 
As atividades nos dias de oficinas permitiram algumas experiências, e vimos que a câmera desperta rapidamente um interesse em aprender a mexer e testar diversas gravações.

\subsection{EDIÇÃO - montar a história e criar efeitos no computador pode fazer parte da brincadeira}

Criança A: Olha... Eu sou antigo (risos).

Pesquisador(a): Isso foi porque você escolheu o filtro preto e branco?

Criança A: Isso. Nossa... Eu sou antigo!

Estamos todos muitos acostumados a ver e a interpretar narrativas audiovisuais, com uma linguagem que é própria de cortes e decisões resultantes da edição dessas mesmas narrativas. Carrière (2007) comenta que não surgiu uma linguagem autenticamente nova até o momento em que os cineastas começaram a cortar o filme em cenas. Assim, nascia a edição. E hoje, como ele diz,

Interpretamos, corretamente e sem esforço, essas imagens justapostas, essa linguagem. Nem percebemos mais essa conexão elementar, automática, reflexiva como uma espécie de sentido extra, essa capacidade já faz parte do nosso sistema de percepção. (p. 14)

É esse nosso sistema de percepção que nos indica, por exemplo, que um filtro nas cores preto e branco pode dar ideia de ser algo antigo, ou que um plano mais aberto quer mostrar a dimensão do local enquadrado pela câmera; que um detalhe desse mesmo local, quando mostrado em destaque, num plano mais fechado e logo em seguida ao plano mais aberto que acabamos de ver, está indicando que o assunto em destaque terá uma certa importância na narrativa. São interpretações que costumamos fazer sem esforço.

Quando nos tornamos produtores, assim como as crianças nos mostraram, realizamos as nossas escolhas, criando uma narrativa audiovisual que leva em conta todas essas referências às quais estamos acostumados. As mudanças e as criações das crianças experimentando a edição de suas histórias no computador nos mostraram parte disso:

Criança $B$, indicando que queria o castelo no meio de sua cena, mas não necessariamente o castelo deveria aparecer como um detalhe:

Criança B: Pode fazer esse do castelo aparecer mais no meio?

Pesquisador(a): Cortar e colocar no meio?

Criança B: Não. Só aparecer mais no meio.

Revista Educação Online, Rio de Janeiro, n. 36, jan-abr 2021, p. 90-103 
Criança A, escolhendo efeitos durante a edição:

Criança A: Ué, mas tá girando?

Pesquisador(a): É porque você escolheu esse efeito, lembra?

Criança A: Nossa, parece que alguém tá assim... Meio câmera escondida, meio atividade paranormal.

Pesquisador(a): Mas se você quiser tirar o efeito, a gente pode tirar.

Criança A: Não! Gostei!

A edição é a parte final, para que a narrativa audiovisual chegue ao objetivo traçado no roteiro. É uma linguagem sutil e, ao mesmo tempo, complexa, como nos fala Gardies (2008, p.86), é "capaz de transcrever com agilidade e precisão não só os acontecimentos e os comportamentos, mas também os sentimentos e as ideias". Brincamos e experimentamos durante as oficinas, ao mesmo tempo em que as criações surgiram e tiveram seu percurso realizado do roteiro até a finalização no momento da edição.

As ferramentas e os recursos necessários à escrita dos roteiros, à produção e gravação das cenas e à edição final das narrativas foram colocados à disposição das crianças, e elas se utilizaram deles ora com propriedade, ora com curiosidade. Carrière (2014) nos fala sobre o processo narrativo com imagens e sons e sobre a imagem em movimento ao alcance de todos, já no ano de 1920:

Ao contrário da escrita, em que as palavras estão sempre de acordo com um código que você deve saber ou ser capaz de decifrar (você aprende a ler a escrever), a imagem em movimento estava ao alcance de todo mundo. Uma linguagem não só nova, como também universal: um antigo sonho. (p. 17 e 18)

E esse sonho cresceu. Ganhou o mundo. Não importa a idade. Tendo curiosidade, tendo um equipamento simples em mãos para produzir, o código audiovisual pode ser compreendido com facilidade e quase como uma linguagem universal.

\section{Considerações finais}

O acesso das crianças e o consumo por elas de histórias narradas com imagens e sons é bem diverso, e isso foi possível perceber tanto nas respostas delas nas rodas de conversas, quanto nos roteiros livremente criados para contarem o que tivessem vontade. Apareceram histórias com enredos bem variados, desde príncipe e princesa que viveram felizes para sempre, passando 
por fantasma que assustava as pessoas, personagens mutantes vivendo em outra dimensão e uma família que vai passear e encontra uma árvore que devorava seres humanos. As histórias criadas por elas, de alguma maneira, remetiam às histórias que liam e aos desenhos e filmes que viam.

Quando estamos em contato com algum produto audiovisual, seja ele qual for, composto por uma narrativa longa ou curta e sem importar se nos desperta maior ou menor interesse, sempre, de alguma maneira, nos apropriamos daquilo que estamos vendo e ouvindo. Formamos nossas opiniões, por vezes, fazemos algum juízo de valor, nos identificamos mais ou menos com o conteúdo, determinamos por quanto tempo estaremos atentos àquela narrativa, entre outros. Apropriações que as crianças igualmente fazem sobre os conteúdos audiovisuais a que têm acesso e que também vão colaborando para a formação de seus repertórios. E, ainda, quando incentivadas e quando há interesse por parte delas, enquanto produtoras de cultura que também são, produzem suas próprias histórias e nelas nos contam, de alguma forma, sobre suas questões e visões de mundo, mostram parte do repertório que têm e que trazem sobre como criar e contar uma história, sobre como devem adequar o conteúdo escolhido e criado por elas para a linguagem audiovisual.

Trilhando o caminho da arte, da criatividade e da livre expressão de ideias, que, aos poucos, ganham o formato de um roteiro e de uma narrativa com imagens e sons, foi também possível perceber o quanto é enriquecedor deixar que as crianças tragam suas histórias, sem que um tema seja definido previamente, exercitando livremente a imaginação e com total liberdade para criar. É também um pouco do "outro tempo" do qual nos fala Fresquet (2013):

Em geral, os centros educativos tendem a considerar as atividades realizadas com a imaginação como tarefas restritas ao campo das artes e, quando algum professor arrisca "imaginar" em suas aulas sobre outros temas, isso é considerado como "tempo perdido". Em busca desse "tempo perdido" é que conseguimos ganhar outro tempo, cuja potência criativa nos aproxima de outros modos de saber, da descoberta e da invenção. (p.29)

Talvez, seja encontrando cada vez mais esse "outro tempo" - e que nada tem de "tempo perdido" - que tenhamos as pistas para enriquecer e incentivar ainda mais as produções e reflexões das crianças, nos muitos espaços por onde circulam e convivem, sejam eles a escola ou tantos outros, com a certeza de que as respostas encontradas também não serão fechadas e que nos levarão a Revista Educação Online, Rio de Janeiro, n. 36, jan-abr 2021, p. 90-103 
outras perguntas. E nós adultos temos um papel importante nessa mediação educativa, colaborando para que ela seja "significativa, crítica, sensível e informada em relação à cultura das mídias", como nos dizem Fantin e Rivoltella (2010, p.92), pensando ainda em outras possibilidades para a prática pedagógica nos espaços educativos:

Afinal, as crianças convivem com essa realidade e, brincando, vão interagindo, aprendendo e construindo novas relações entre si, com os pares e com a cultura, e a educação não pode deixar de mediar essas produções de sentidos. Para além da homologação da cultura e da crítica ao consumismo na era digital, as mediações educativas podem assegurar a diversidade de experiências e potencializar as oportunidades considerando as inúmeras relações que as crianças estabelecem nos cenários contemporâneos. (FANTIN; RIVOLTELLA, 2010, p.103)

Convivendo com as narrativas audiovisuais, criando e contando histórias, valores são construídos e significados são repensados. O ritmo é acelerado, as mudanças acontecem rápido, e as crianças parecem não ter dificuldades para acompanhar. Elas entram com facilidade nessa dinâmica, e produzir histórias com áudio e vídeo parece ser um atrativo para elas. Como então aproveitar e potencializar esse recurso para a sua formação e de todos nós, enquanto sujeitos, cidadãos e educadores? No trajeto percorrido, vimos ser possível colaborar para que as experiências sejam de verdade experiências e para que nos toquem no sentido de nos transformarem de verdade, como nos disse Larrosa (2002). E a educação, se assim desejar, pode se apropriar cada vez mais do audiovisual como uma ferramenta, e da criação de histórias com imagens e sons, colaborando para alguns dos processos de ensino e aprendizagem.

\section{Referências bibliográficas}

BONDÍA, Jorge Larrosa. Notas sobre a experiência e o saber de experiência. Revista Brasileira da Educação, Rio de Janeiro, n. 19, p.24, jan./abr. 2002.

CANCLINI, Nestor Garcia. Consumo, acesso y sociabilidade. Revista

Comunicação, Mídia e Consumo. São Paulo, v.6, n. 16, p. 111-127, 2009.

CARRIÈRE, Jean Claude. A linguagem secreta do cinema. Rio de Janeiro: Nova Fronteira, 2014. 
FANTIN, Monica; RIVOLTELLA, P.C. Crianças na era digital: desafios da comunicação e da educação. Revista Estudos Universitários, Sorocaba, v. 36, n.1, p. 89-104, jun.2010.

FERNANDES, Adriana Hoffmann. Infância e cultura: o que narram as crianças na contemporaneidade? 2009. Dissertação (Doutorado em Educação) Programa de Pós graduação em Educação, Universidade do Estado do Rio de Janeiro, Rio de Janeiro, 2009.

FRESQUET, Adriana. Cinema e educação: reflexões e experiências com professores e estudantes de educação básica, dentro e "fora" da escola. Belo Horizonte: Autêntica, 2013.

GARDIES, René. Compreender o cinema e as imagens. Lisboa: Edições Texto e Grafia, 2008.

MACEDO, N. M. R. et al. Encontrar, compartilhar e transformar: reflexões sobre a pesquisa-intervenção com crianças. In: PEREIRA, R. M.; MACEDO, N. M. R. (Orgs.). Infância em pesquisa. Rio de Janeiro: Nau, 2012. p.87-107

MARTIN, Marcel. A linguagem cinematográfica. São Paulo: Ed. Brasiliense, 2003.

SALGADO, Raquel Gonçalves. Ser criança e herói no jogo e na vida: a infância contemporânea, o brincar e os desenhos animados. 2005. Tese (Doutorado em Psicologia), Departamento de Psicologia, PUC-Rio, Rio de Janeiro, 2005. 